\title{
Ruído em Consultórios Odontológicos pode Produzir Perda Auditiva?
}

\author{
Can Noise in Dental Clinic Produce Hearing Loss?
}

\author{
Edmir Américo Lourenço *, Janaína Medina da Rocha Berto **, Sávio Butignolli Duarte ***, \\ João Paulo Martins Greco****.
}

\author{
* Doutor em Medicina pela UNIFESP. Professor Titular da Disciplina de Otorrinolaringologia da Faculdade de Medicina de Jundiaí - SP. \\ *** Médica graduada na Faculdade de Medicina de Jundiaí - SP. Médica Residente de Otorrinolaringologia do CEMA-SP. \\ **** Médico graduado na Faculdade de Medicina de Jundiaí - SP. Médico Residente de Cirurgia da Faculdade de Medicina de Jundiaí - SP. \\ ***** Médico graduado na Faculdade de Medicina de Jundiaí - SP. Médico Residente de Anestesiologia da Faculdade de Medicina de Jundiaí - SP \\ Instituição: Disciplina de Otorrinolaringologia da Faculdade de Medicina de Jundiaí (FMJ) \\ Jundiaí / SP - Brasil. \\ Endereço para correspondência: Edmir Américo Lourenço - Rua do Retiro, 424 - 5. andar. conjuntos 53 e 54 - Bairro: Anhangabaú - Jundiaí / SP - Brasil - CEP: \\ 13209-000 - Telefone: (+55 11) 4521-1697 e 4521-3181. Celular: (+55 11) 8303-3871 - E-mail: edmirlourenco@ibest.com.br \\ Artigo recebido em 19 de Outubro de 2010. Artigo aprovado em 10 de Dezembro de 2010
}

\section{RESUMO}

Introdução:

Objetivo:

Método:

A perda auditiva sensorial e irreversível induzida por ruído é a maior causa ocupacional evitável de perda auditiva no mundo. Os dentistas são profissionais da saúde expostos a ruídos provenientes dos equipamentos em seus consultórios e podem sofrer perdas auditivas.

Medir intensidades de ruído emitidas pelos motores de alta rotação (mar) utilizados em consultórios odontológicos públicos e privados, verificar se são lesivas para a orelha humana e comparar os resultados obtidos entre estes serviços. Estudo de série, prospectivo, com medidas das intensidades de ruído em dBNA com um decibelímetro Minipa MSL-1352C, USA em quatro consultórios odontológicos do serviço público e quatro particulares em Jundiaí-SP, inicialmente do ruído ambiental basal em cada consultório, durante cinco minutos e depois, do ruído emitido pelo motor de alta rotação(mar) em funcionamento durante cinco minutos para obter-se as médias.

Resultados: $\quad$ Públicos: 1) basal=56,4dB; mar=77,2dB. 2) basal=61,7dB; mar=73,7dB. 3) basal=61,07dB; mar=75,04dB. 4) basal=63,6dB; mar=77,3dB. Particulares: 1 ) basal=60,7dB; $\operatorname{mar}=79,1 \mathrm{~dB}$. 2) basal=60,7dB; $\operatorname{mar}=83,1 \mathrm{~dB}$. 3) basal=58,4dB; mar=75,5dB. 4)basal=63dB; $\operatorname{mar}=76 \mathrm{~dB}$.

Conclusões: As intensidades aferidas de ruído emitido por motores de alta rotação utilizados em consultórios odontológicos públicos e privados encontram-se abaixo dos limites nocivos à saúde auditiva. No serviço público, a intensidade de ruído basal é superior à dos consultórios particulares, contudo a dos motores de alta rotação é maior nos consultórios particulares.

Palavras-chave: ruído ocupacional, ambiente de trabalho, odontologia, instrumentos odontológicos, perda auditiva.

\section{SUMMARY}

Introduction:

The sensorial hearing loss and irreversible noise induced is the major evitable occupational cause of hearing loss worldwide. The dentists are health professionals exposed to noises from equipment in their clinics and may suffer hearing losses.

Objective:

Measure the noise intensities emitted by the high rotation motors (mar) used in public and private dental clinics, check whether they are harmful for the human ear and compare the results obtained in such services.

Method:

Serial, retrospective study with measures of the noise intensities in dBNA with a decibelimeter Minipa MSL-1352C, USA, in four dental clinics of the public service and four private clinics in Jundiaí-SP, initially from the basal environment noise in each clinic, during five minutes and then from the noise emitted by the high rotation motor (mar) in operation during five minutes to obtain the averages.

Results: Public clinics: 1)basal medium $=56.4 \mathrm{~dB} ;$ mar $=77.2 \mathrm{~dB}$. 2) basal medium $=61.7 \mathrm{~dB} ;$ mar $=73.7 \mathrm{~dB}$. 3) basal medium $=61.07 \mathrm{~dB} ;$ mar $=75.04 \mathrm{~dB}$. 4)basal medium $=63.6 \mathrm{~dB} ; \mathrm{mar}=77.3 \mathrm{~dB}$. Private clinics: 1)basal medium $=60,7 \mathrm{~dB} ; \mathrm{mar}=79,1 \mathrm{~dB} .2)$ basal $=60,7 \mathrm{~dB} ; \mathrm{mar}=83,1 \mathrm{~dB} .3)$ basal $=58,4 \mathrm{~dB} ; \mathrm{mar}=75,5 \mathrm{~dB} .4) \mathrm{basal}=63 \mathrm{~dB} ; \mathrm{mar}=76 \mathrm{~dB}$.

Conclusion: The intensities measured of noise emitted by high rotation motors used in public and private dental clinics are below the limits harmful to the auditory health. In the public service, the basal medium noise intensity is higher than that of the private clinics, however the one of the high rotation motors is higher in the private clinics.

Keywords: 


\section{INTRODUÇÃO}

A perda auditiva induzida por ruído (PAIR) é uma perda auditiva neurossensorial, predominantemente coclear, de característica irreversível. Esta doença ocorre devido a uma história prolongada de exposição ao ruído de alta intensidade e tem evolução gradual e progressiva. A perda auditiva ocorre quando há uma impossibilidade de recepção do som por lesão das células ciliadas da cóclea e iniciase em frequências altas, geralmente em $4000 \mathrm{~Hz}$ (quatro quilohertz). Cessada a exposição ao ruído, a perda auditiva tende a se estabilizar.

A PAIR atinge inicialmente frequências agudas, sendo que as primeiras dificuldades surgidas são de ouvir campainhas e toques de telefone. Posteriormente, com o avanço da doença, surgem as dificuldades em todas as frequências, por isso o diagnóstico muitas vezes é tardio.

Esta é a doença ocupacional de maior incidência e a maior causa evitável de perda auditiva no mundo, segundo Lopes Filho e Campos (1). Os controles auditivos periódicos de indivíduos expostos, bem como os níveis de intensidade sonora permitidos por 8 horas de exposição diárias ao ruído são no máximo de 85 decibels e estão bem regulamentados, conforme o anexo I das normas regulamentadoras números 7 e 15 da Legislação Trabalhista Brasileira, como está exemplificado na Tabela $1(2,3)$.

Os odontologistas são profissionais da saúde expostos a diversos ruídos em seus consultórios, produzidos e emitidos por canetas de alta e baixa rotação, sugador, compressor, cuspideira, peça reta, fotopolimerizador, autoclave e ar condicionado, contudo são as primeiras as consideradas como tendo maior potencial lesivo à orelha humana. Em virtude disso, diferentes estudos têm analisado a relação entre a intensidade dos ruídos no consultório odontológico, a carga horária do profissional, o tempo de atividade profissional e a perda auditiva nesses profissionais (4). O que se constata na maioria deles é que, mesmo expostos a níveis de intensidade sonora menores que 85 decibels, mas com tempo de exercício de profissão superior a cinco anos, apresentam perdas auditivas $(5,6)$.

Para prevenir o desencadeamento ou agravamento da perda auditiva ocupacional, deve ser realizado um controle audiológico anual através de no mínimo uma audiometria, além de proteção individual. Abaixo temos na Tabela 1 o Anexo I da Norma Regulamentadora número 15, que estabelece os limites de tolerância para ruído contínuo ou intermitente (3).

Os objetivos deste trabalho são: 1) medir intensidades de ruído em consultórios odontológicos públicos e
Tabela I . Anexo I da Norma Regulamentadora ${ }^{\circ}$ I 5: limites de tolerância para ruído contínuo ou intermitente.

\begin{tabular}{cc}
\hline Nível de ruídodB(NA) & Máxima exposição diária permissível \\
\hline 85 & 8 horas \\
86 & 7 horas \\
87 & 6 horas \\
88 & 5 horas \\
89 & 4 he 30 min \\
90 & 4 horas \\
91 & 3 he 30 min \\
92 & 3 horas \\
93 & 2 he 40 min \\
94 & 2 he 15 min \\
95 & 2 horas \\
96 & 1 he 45 min \\
98 & 1 he I5 min \\
100 & I hora \\
102 & 45 minutos \\
104 & 35 minutos \\
105 & 30 minutos \\
106 & 25 minutos \\
108 & 20 minutos \\
\hline
\end{tabular}

privados, provenientes das canetas movidas por motor de alta rotação e o ruído basal ambiental, verificar se apresentam intensidades lesivas para a orelha humana; 2) comparar os resultados obtidos entre o serviço público e privado.

\section{MÉTODO}

Os locais de medição foram consultórios odontológicos de Unidades Básicas de Saúde (UBS) ou outros serviços públicos e consultórios particulares em Jundiaí, Estado de São Paulo, Brasil, nos quais o profissional, o auxiliar e o paciente estão expostos diariamente, após contato e concordância dos envolvidos. Protocolado no SISNEP, o trabalho obteve aprovação do Comitê de Ética em Pesquisa da Instituição de Ensino sob número 314/ 2008. Foi realizada a medição da intensidade do ruído em quatro consultórios odontológicos do sistema público de saúde e em quatro consultórios particulares. Para a medição, foi utilizado um decibelímetro marca Minipa ${ }^{\circledR}$, modelo MSL-1352C, procedência USA, configurado da seguinte forma: tempo de resposta lento (slow), que mediu o nível de ruído em decibels (dBNA), com escala de 30 a 130 dB, por um período de cinco minutos, a uma distância de vinte centímetros da caneta e do motor de alta rotação, das marcas Dabi Atlante ${ }^{\circledR}$, Kavo $^{\circledR}$, e Micro Dente ${ }^{\circledR}$, utilizadas pelos diferentes profissionais em seus consultórios. Foi medida inicialmente a intensidade do ruído ambiental em cada consultório, durante cinco minutos e a esse valor denominou-se Basal. Em seguida, foi feita a medição da 


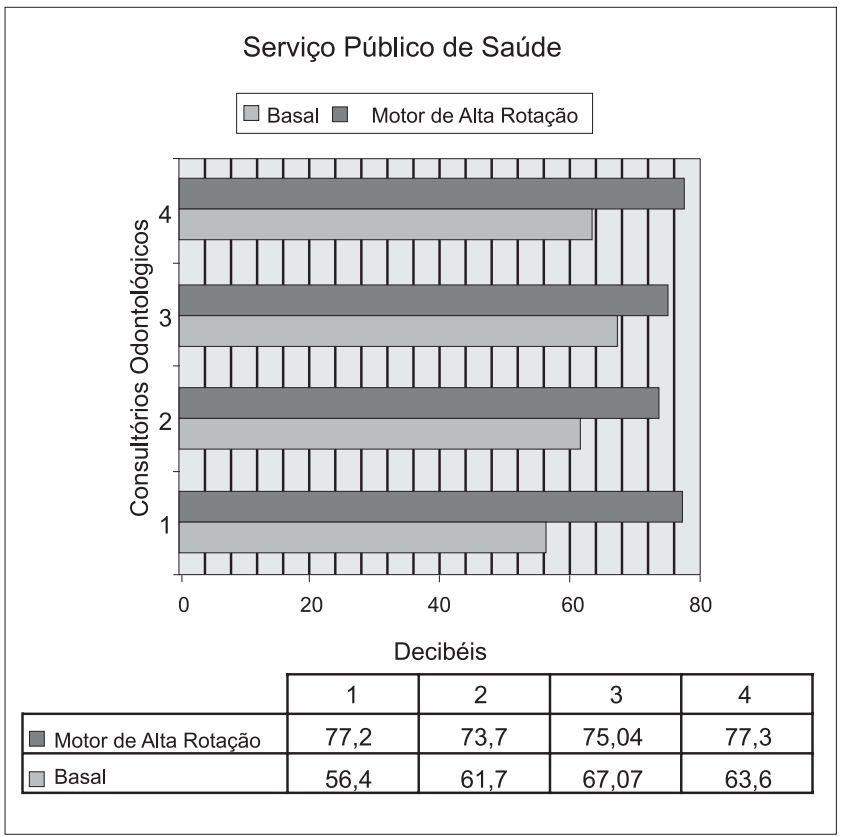

Gráfico 1. Intensidades médias em decibels do ruído basal e dos motores de alta rotação aferidos em quatro consultórios odontológicos do serviço público em Jundiaí - SP.

intensidade do ruído emitido pelo equipamento citado, também por cinco minutos. Nestas duas situações, foi calculada a média em decibels da intensidade de ruído.

Não foi realizada análise estatística dos resultados, devido ao tipo de registro gráfico do decibelímetro utilizado e ao fato de que o objetivo principal do estudo foi o de determinar se as intensidades aferidas seriam lesivas para a orelha humana.

\section{RESULTADOS}

Consultórios odontológicos do sistema público de saúde de Jundiaí (Gráfico 1):

1. Basal, com ruído ambiental (conversação): média de $56,4 \mathrm{~dB}$. Motor de alta rotação (Dabi Atlante ${ }^{\circledR}$, tempo de uso de quatro anos e meio, tempo de exposição de 3 horas diárias), média de 77,2 dB;

2. Basal, com ruído ambiental (conversação, ventilador, e consulta na cadeira ao lado): média de $61,7 \mathrm{~dB}$. Motor de alta rotação (Dabi Atlante ${ }^{\circledR}$, tempo de uso de quatro anos, tempo de exposição de 4 horas diárias), média de $73,7 \mathrm{~dB}$;

3. Basal, com ruído ambiental (conversação): média de $67,1 \mathrm{~dB}$. Motor de alta rotação (Kavo ${ }^{\circledR}$, tempo de uso indefinido, tempo de exposição um terço da carga horária do profissional), média de 75,0 dB;

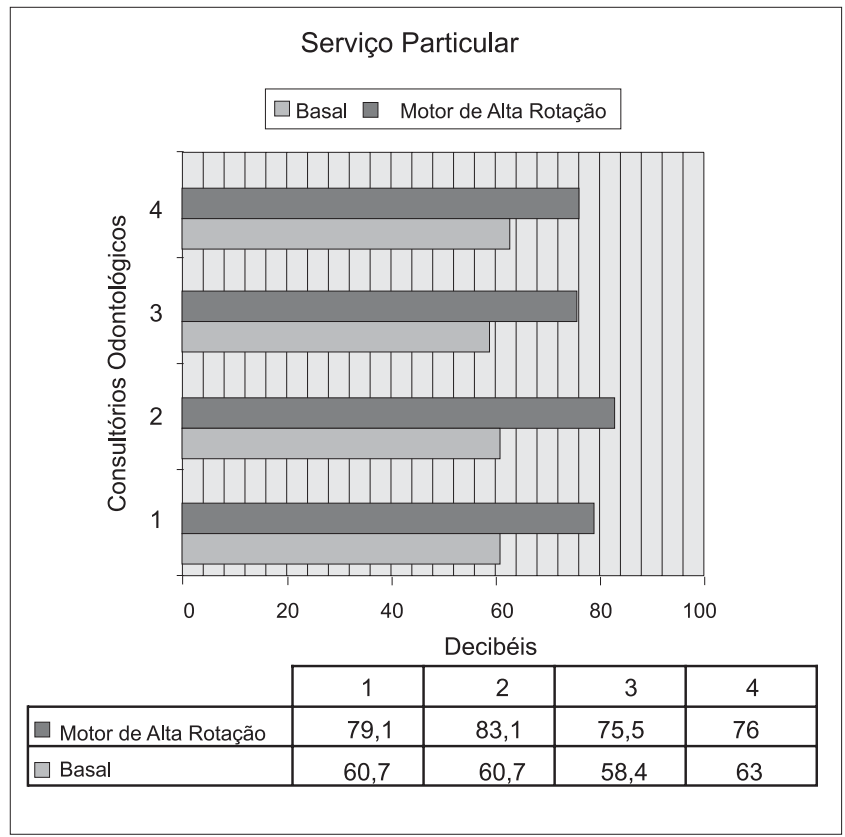

Gráfico 2. Intensidades médias em decibels de ruído basal e dos motores de alta rotação aferidos em quatro consultórios odontológicos particulares em Jundiaí - SP.

4. Basal, com ruído ambiental (rádio e ventilador): média de 63,6 dB. Motor de alta rotação (Kavo ${ }^{\circledR}$, tempo de uso superior a um ano, tempo de exposição indefinido), média de $77,3 \mathrm{~dB}$.

Consultórios odontológicos particulares de Jundiaí (Gráfico 2):

1. Basal, com ruído ambiental (conversação, sugador, som ambiente): média de 60,7 dB. Motor de alta rotação (Kavo ${ }^{\circledR}$, tempo de uso de um ano, tempo de exposição de três horas diárias), média de 79,1 dB;

2. Basal, com ruído ambiental (conversação, sugador, som ambiente): média de 60,7 dB. Motor de alta rotação $\left(\mathrm{Kavo}^{\circledR}\right.$, tempo de uso de cinco anos, tempo de exposição de cinco horas diárias), média de 83,1 dB;

3. Basal, com ruído ambiental (Ar condicionado, sugador e conversação): média de 58,4 dB. Motor de alta rotação $\left(\mathrm{Kavo}^{\circledR}\right.$, tempo de uso de dois anos, tempo de exposição de três horas diárias), média de $75,5 \mathrm{~dB}$;

4. Basal, com ruído ambiental (som ambiente, conversação, sugador): média de 63,0 dB. Motor de alta rotação (Micro Dente ${ }^{\circledR}$, tempo de uso de cinco anos, tempo de exposição de três horas diárias), média de 76,0 dB.

\section{DISCUSSÃO}

A preocupação com as perdas auditivas de origem ocupacional se deve ao fato de que essa é a doença ocupacional de maior incidência e a maior causa evitável 


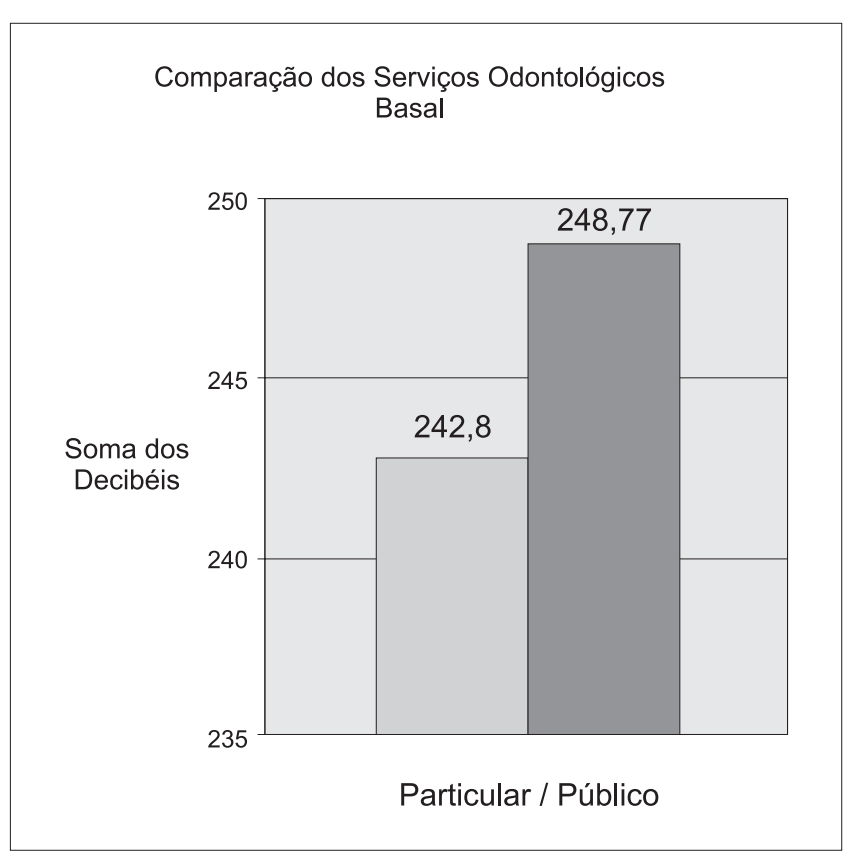

Gráfico 3. Comparação entre a somatória das médias do ruído basal de consultórios odontológicos de serviços particular e público em Jundiaí -SP.

de perda auditiva no mundo. Cessada a exposição ao ruído, tende a se estabilizar, sendo portanto a detecção da mesma a ação profilática mais efetiva. Ruídos emitidos por eletrodomésticos, que foram motivo de preocupação das autoridades no passado quanto à manutenção da saúde auditiva nos lares, restaurantes e demais locais onde são utilizados esses aparelhos, têm se reduzido com o aperfeiçoamento tecnológico (7). Assim também os antigos motores de alta rotação de uso odontológico apresentavam teto sonoro superior a 85 decibels e há muitos trabalhos na literatura comprovando perdas auditivas nesses profissionais, contudo os modernos, sob manutenção técnica periódica e adequadamente lubrificadas, apresentam nível de ruído inferior a 85 decibels, segundo Scully et al (5), achado coincidente com o que observamos nos equipamentos analisados. O Gráfico 1 mostra as intensidades médias em decibels de ruído basal e dos motores de alta rotação aferidos nos consultórios odontológicos do serviço público no município de Jundiaí-SP e o Gráfico 2 mostra os mesmos achados em consultórios odontológicos particulares no município de Jundiaí - SP, podendo-se observar que nenhum dos valores extrapola o limite de $85 \mathrm{~dB}$. Mesmo que consideremos que os profissionais podem ter outros locais de atuação e estes achados correspondam a um único período de trabalho, o máximo preconizado pela Norma, que é de $85 \mathrm{~dB}$, é considerado para 8 horas de exposição contínua. Tais achados nos animam, por estarem de acordo com a Legislação Brasileira. Esta confirmação nos tranquiliza sob o aspecto preventivo das perdas auditivas ocupacionais

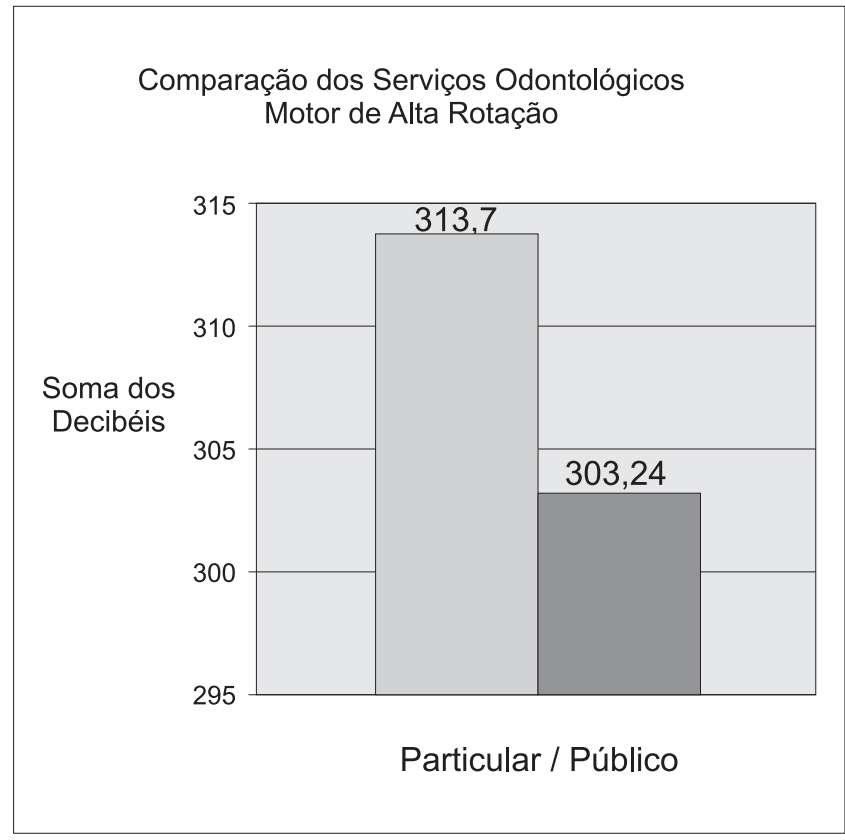

Gráfico 4. Comparação entre a somatória das médias de ruído dos motores de alta rotação de consultórios odontológicos de serviços particular e público em Jundiaí SP.

em profissionais da área odontológica, até alguns anos atrás motivo de grande preocupação dos profissionais da área de medicina preventiva (4). Quanto à somatória das médias de ruído basal e dos motores de alta rotação, os Gráficos 3 e 4 comparam os achados nos consultórios odontológicos de serviços particular e público no município de Jundiaí SP, demonstrando que o ruído basal médio foi $2,4 \%$ maior no serviço público devido ao ruído ambiental elevado, enquanto o ruído médio dos motores de alta rotação foi 3,3\% maior nos consultórios das clínicas privadas. Por esse motivo, devem ainda ser realizados esforços para que sejam abandonados e trocados todos os equipamentos odontológicos arcaicos.

Apesar de existirem trabalhos que sugerem perdas auditivas em dentistas expostos a ruídos inferiores a $85 \mathrm{~dB}$, os ruídos emitidos pelos equipamentos aferidos neste trabalho estão dentro dos limites aceitos para não causar PAIR, conforme a Legislação Brasileira, possibilitando readequações profissionais quanto ao seu tempo de exposição.

\section{CONCLUSÕES}

1. As intensidades de ruído aferidas, provenientes dos equipamentos utilizados nos consultórios odontológicos, tanto públicos quanto privados, encontram-se abaixo dos limites considerados nocivos à saúde auditiva. 
2. No serviço público, a intensidade de ruído basal é superior à dos consultórios particulares, contudo a dos motores de alta rotação é maior nos consultórios particulares.

\section{REFERÊNCIAS BIBLIOGRÁFICAS}

1. Lopes Filho O, Campos CAH. Tratado de Otorrinolaringologia. São Paulo, Roca, 1994. p.941.

2. www.mte.gov.br/legislação/normas_regulamentadoras/ nr_07_.pdf

3. www.mte.gov.br/legislação/normas_regulamentadoras/ nr_15_.pdf
4. Trucco RE. Traumatismo acústico del odontólogo. Rev Fed Odontol Colomb. 1985, 34(151):103-10.

5. Scully C. Occupational hazards to dental staff. Br Dent J. 1991, 171:237-44.

6. Ruschel CV, ZiembowiczLAB, Sleifer P, Mattos AP. Perda auditiva induzida pelo ruído em cirurgiões-dentistas. Rev Bras Odontol. 2005, 62(1,2):25-7.

7. Toledo RN et al. Medida do nível de ruído produzido por aparelhos eletrodomésticos. Acta Awho. 1999, 18(3):1247. 